Published in final edited form as:

Sci Transl Med. 2017 January 25; 9(374): . doi:10.1126/scitranslmed.aai9338.

\title{
RON kinase: A target for treatment of cancer-induced bone destruction and osteoporosis
}

\author{
Kelsi Andrade ${ }^{1,6, \wedge}$, Jaime Fornetti ${ }^{1, \wedge}$, Ling Zhao ${ }^{1}$, Scott C. Miller ${ }^{2}$, R. Lor Randall ${ }^{3}$, Neysi \\ Anderson ${ }^{1}$, Susan E. Waltz ${ }^{4}$, Mark McHale ${ }^{5}$, and Alana L. Welm ${ }^{1,{ }^{*}}$ \\ ${ }^{1}$ Department of Oncological Sciences, Huntsman Cancer Institute, University of Utah, Salt Lake \\ City, Utah, 84112 \\ 2Department of Radiology and Imaging Sciences, Division of Radiobiology, University of Utah, \\ Salt Lake City, Utah, 84112 \\ ${ }^{3}$ Department of Orthopaedics, University of Utah, Salt Lake City, Utah, 84112 \\ ${ }^{4}$ Department of Cancer and Cell Biology, University of Cincinnati and Cincinnati Veterans Affairs \\ Medical Center, Cincinnati, Ohio, 45267 \\ ${ }^{5}$ Aslan Pharmaceuticals, Singapore, 089824
}

\section{Abstract}

\begin{abstract}
Bone destruction occurs in aging and numerous diseases, including osteoporosis and cancer. Many cancer patients have bone osteolysis that is refractory to state-of-the-art treatments, which block osteoclast activity with bisphosphonates or by inhibiting the RANKL pathway. We previously showed that macrophage-stimulating protein (MSP) signaling, which is elevated in approximately $40 \%$ of breast cancers, promotes osteolytic bone metastasis, but it was unknown whether this was due to activation of the MSP signaling pathway in the tumor cells or in the bone microenvironment. Here we show that MSP signals through host expression of its receptor, RON tyrosine kinase, to directly activate osteoclasts by a previously undescribed pathway that is complementary to RANKL signaling and converges on SRC. Genetic or pharmacologic inhibition of RON kinase blocked cancer-mediated bone destruction and osteoporosis in several mouse models. Furthermore, the RON kinase inhibitor BMS-777607/ASLAN002 altered markers of bone turnover in a first-in-human clinical cancer study, indicating potential for normalizing bone loss in patients. These findings uncover a new therapeutic target for pathogenic bone loss and provide a rationale for treatment of bone destruction in various diseases with RON inhibitors.
\end{abstract}

\footnotetext{
*Correspondence: alana.welm@ @ci.utah.edu.

${ }^{6}$ Current address: Stephenson Cancer Center, University of Oklahoma Health Science Center, Oklahoma City, OK 73014 ${ }^{\wedge}$ These authors contributed equally.

Author contributions: K.A. and J.F. designed and performed experiments, acquired, analyzed and interpreted data, and prepared the manuscript; L.Z. produced and purified recombinant MSP; S.C.M. contributed to experimental design and data collection and interpretation; R.L.R acquired and provided human bone metastasis samples; S.E.W provided Ron $\mathrm{TK}^{-/}$mice; M.M. provided information and samples related to ASLAN002 and the Phase 1 study; A.L.W. oversaw experiments and data analysis and prepared the manuscript; all authors reviewed and commented on the manuscript.

Competing interests: M.M. is an employee of Aslan Pharmaceuticals. Other authors declare no competing interests.

Data and materials availability: All data are provided in the manuscript. Materials for these studies are available from the authors through a material transfer agreement.
} 


\section{Introduction}

Bone-destructive pathological conditions cause significant morbidity in the United States. Approximately 44 million Americans have osteoporosis, a condition of bone loss and structural weakness. Osteoporosis primarily affects post-menopausal women because of their low estrogen, and an estimated $50 \%$ of women over the age of 50 experience an osteoporosis-related fracture (1). A less common but even more debilitating cause of osteolytic bone destruction is metastasis of certain cancers to bone, which affects 400,000 individuals annually (2). Notably, over $70 \%$ of metastatic breast cancer patients have bone metastasis. These lesions cause severe bone loss, resulting in profound pain, nerve compression, hypercalcemia, and debilitating fractures $(3,4)$. Similar problems are seen in multiple myeloma, where approximately $90 \%$ of patients have bone lesions, and $80 \%$ experience a pathological fracture as a result of bone loss in spite of treatment (5).

Skeletal integrity is normally sustained by an equilibrium between bone resorption by osteoclasts and bone formation by osteoblasts. In conditions such as osteoporosis and osteolytic metastasis, bone destruction results from disruption in the balance between osteoclast and osteoblast activity. In metastasis, hyperactivated osteoclasts excessively resorb bone, releasing growth factors such as TGF $\beta$ from the bone matrix into the bonetumor microenvironment. Such factors can act on the tumor to drive growth and production of proteins such as parathyroid hormone-related peptide and interleukin-11, which stimulate receptor activator of nuclear factor-kB ligand (RANKL) secretion by osteoblasts. RANKL is a key mediator of osteoclast differentiation and activity, thus completing a "vicious cycle" of bone resorption and tumor growth at sites of osteolytic metastasis $(6,7)$.

Current treatments for bone loss include bisphosphonates and/or the RANKL antagonist denosumab. Bisphosphonates incorporate into the skeleton where they are taken up by osteoclasts during resorption, resulting in decreased osteoclast activity and reduced bone loss. Bisphosphonates are routinely used for clinical management of cancer metastasis, osteoporosis, and other forms of bone loss for which they reduce skeletal-related events such as fractures by approximately one-third, diminish pain and increase quality of life (8). Similar to bisphosphonates, denosumab also targets osteoclasts; however, its mechanism of action is to reduce osteoclast differentiation and function by blocking RANKL. In clinical testing, denosumab treatment significantly improved the onset of pain, time to skeletalrelated events (approximately $18 \%$ improvement), and bone turnover markers compared to bisphosphonates $(9,10)$. The most notable effects of denosumab to date have been in breast and prostate cancers (11). In multiple myeloma patients, however, denosumab was not better at delaying time-to-skeletal-related events than the bisphosphonate zoledronic acid, and there was poorer survival in the group of patients who received denosumab (12). Thus, denosumab is FDA-approved for treatment of osteoporosis and some, but not all, types of cancer involving bone.

Despite current therapies, $30-50 \%$ of patients with bone metastasis eventually progress to develop new bone lesions or serious skeletal complications (10). Once cancer has metastasized to bone it is generally incurable. So far, no significant improvement in disease progression or overall survival has been documented with denosumab (11). However, 
successful normalization of bone turnover by treatment with the bisphosphonate zoledronic acid correlated with improved overall survival in a subset of metastatic cancer patients who had high baseline bone turnover (13). Also, in mouse models, metastasis-induced bone destruction contributes to muscle wasting through altered growth factor signaling (14). These studies suggest that better control of osteolysis may both improve quality of life and improve cancer outcomes. Together, as indicated by a recent multidisciplinary consensus conference (2), these issues highlight a large unmet clinical need to treat cancer patients with progressing bone metastasis, underlining the importance of identifying new therapies to control pathogenic osteoclast activation.

Recently appreciated for its role in bone metastasis is the macrophage-stimulating protein (MSP; also known as human macrophage stimulating 1, MST1, or mouse hepatocyte growth factor-like protein, HGFL) signaling pathway. MSP is the only known ligand for the RON receptor tyrosine kinase (also known as MST1R), and RON is one of only two members of a distinct receptor family that also includes c-MET (15). RON is expressed by osteoclasts in vitro (16-18) and is present in bone tissues in vivo (19). RON is also expressed in certain epithelial-derived cells such as keratinocytes, in nociceptive neurons, and in resident tissue macrophages $(19,20)$. To date, no functional role for RON has been demonstrated in osteoclasts, with the exception of two reports showing that stimulation of osteoclasts with MSP in vitro increases osteoclast activity, with no effect on proliferation $(16,21)$. Thus, despite multiple lines of evidence that RON is expressed in mature osteoclasts, very little is known about MSP/RON function in these cells, and there are no published reports on MSP/RON function in bone in vivo.

We previously found that MSP overexpression in mouse mammary tumor cells led to spontaneous bone metastasis (22), but the mechanisms facilitating this process are not known. RON overexpression in mammary tumors does not cause bone metastasis (23), supporting a potential non-cell autonomous mechanism for MSP-driven bone metastasis. In the present report, we examine the role of MSP signaling through host RON in bone loss occurring during bone metastasis and osteoporosis, with the aim of identifying a possible therapeutic agent.

\section{Results}

\section{MSP causes osteolysis by non-cell autonomous activation of RON in metastasis models}

We previously reported that MSP drives spontaneous osteolytic bone metastasis in the PyMT mouse mammary tumor model (22). To investigate the mechanistic basis of MSP-mediated osteolysis, we injected PyMT control or MSP-expressing tumor cells into tibias of syngeneic wild-type (WT) mice or syngeneic mice in which the tyrosine kinase domain of Ron (also known as macrophage stimulating 1 receptor, $M s t 1 r$, and stem cell-derived tyrosine kinase, Stk) had been deleted from the genome (RON TK ${ }^{-/}$mice) (24). MSP-expressing tumor cells caused profound osteolysis in WT bones, but very little osteolysis in $\mathrm{RON} \mathrm{TK}^{-/}$bones (Figure 1A-B). Tumor growth and proliferation were not significantly different between WT and $\mathrm{RON} \mathrm{TK}^{-/-}$hosts (Figure S1A), consistent with our previous work demonstrating that growth rates, proliferation, and apoptosis of these same tumors in the mammary gland is similar in WT and RON TK ${ }^{-/-}$hosts (25). Thus, MSP-expressing tumor cells caused 
osteolysis through a non-cell autonomous mechanism that required the kinase activity of host RON. Similar results were obtained when a human breast cancer cell line (DU4475), which overexpresses endogenous MSP above mean-centered value, similar to our analysis of patient tumor samples ((22)), was injected into bones of WT or RON TK${ }^{-/-}$mice (crossed with immune-deficient NOD.SCID mice and then into the FVB genetic background)

(Figures 1C and S1B-C). These data ensured that our findings were not restricted to mouse tumors or tumors engineered to overexpress MSP. These experiments also ruled out a role for T cells in MSP-mediated osteolysis, as NOD.SCID mice do not have functional T cells and $\mathrm{T}$ cells have been shown to influence osteoclast activity (26).

To begin to address how MSP-expressing tumor cells promote osteolysis, osteoclast numbers were evaluated in our intratibial tumor model to determine whether MSP increases osteoclastogenesis. Staining for the osteoclast marker tartrate-resistant acid phosphatase (TRAP) revealed no significant differences in osteoclast numbers between mice with control or MSP-expressing tumors, in either WT or RON TK ${ }^{-/-}$hosts (Figure S2A-B). Osteoclast numbers were also not statistically different in WT and RON TK ${ }^{-1}$ NOD.SCID mice with DU4475 tumors (Figure S2C-D). These results suggested that the robust osteolysis caused by the MSP/RON pathway is likely mediated through increased osteoclast activity rather than through major differences in osteoclast numbers.

We next investigated whether any pre-existing differences in $\mathrm{RON} \mathrm{TK}^{-/-}$bones might contribute to protection from metastasis-mediated osteolysis. Osteoclast numbers, bone mineral density, and bone formation were assessed in normal, uninjected mice. Again, no significant differences in osteoclast numbers were observed in WT and $\mathrm{RON} \mathrm{TK}^{-/}$bones in either the immune competent FVB background (Figure S3A-B) or the immune deficient NOD.SCID background (Figure S3C-D), indicating that the profound reduction in tumorrelated osteolysis in $\mathrm{RON} \mathrm{TK}^{-/-}$hosts is likely not a result of a pre-existing defect in osteoclast differentiation. To verify that $\mathrm{RON} \mathrm{TK}^{-/-}$bones did not contain fewer osteoclasts, we also investigated whether $\mathrm{RON} \mathrm{TK}^{-/-}$mice had intrinsic differences in bone mineral density or bone formation and found no differences in bone mineral density between WT and $\mathrm{RON} \mathrm{TK}^{-/}$mice (see osteoporosis section below). Bone formation was assessed by in vivo labeling with calcein and alizarin, which revealed comparable mineral apposition rates (MAR) and bone formation rates (BFR) in WT and RON TK ${ }^{-/-}$bones (Figure S4A-C). We also examined bones of mice completely lacking murine $R o n / S t k$ through a different gene targeting strategy (27) to ensure that a tyrosine kinase-independent function of RON was not contributing to bone formation. Again, no differences in bone histomorphometry were found between WT and $S_{t K^{-/}}$mice (Figure S4A, D-E). Consistent with this, osteoclasts and chondrocytes, but not osteoblasts, expressed RON, as measured with immunostaining (Figure S4F); the MC3T3-E1 osteoblast cell line was also negative for RON expression (Figure S4G). These data suggested that general deficiencies in osteoclast numbers, bone structure, or bone formation were not responsible for amelioration of tumor-induced osteolysis in RON TK ${ }^{-/}$hosts. Therefore, we tested the hypothesis that MSP-expressing tumors promote osteolysis through a RON-dependent increase in osteoclast activity, and asked whether RON inhibitors have therapeutic benefit for MSP-induced osteolysis. 


\section{Treatment with RON inhibitors blocks tumor-driven osteolysis}

We tested whether pharmacologic inhibition of RON could protect against osteolysis using both mouse and human tumor models and two different small molecule inhibitors that are selective for RON and MET (OSI-296 and BMS-777607/ASLAN002). OSI-296 is more selective for MET ( $\mathrm{IC}_{50} 42 \mathrm{nM}$ for MET; $200 \mathrm{nM}$ for RON (28)), while BMS-777607/ ASLAN002 is more selective for RON ( $\mathrm{IC}_{50} 3.9 \mathrm{nM}$ for MET; $1.8 \mathrm{nM}$ for RON (29)). Treatment with either drug, beginning three days after tumor injection (pre-osteolysis), significantly inhibited bone destruction from murine PyMT-MSP tumors (Figure 2A-D; preosteolysis panels). BMS-777607/ASLAN002 (but not OSI-296) also prevented the osteolysis caused by human DU4475 cells (Figure 2E-F). RON inhibition did not significantly affect osteolysis induced by PyMT tumors that lacked MSP (Figure S5A-B).

To test RON inhibitors in a more clinically-relevant setting, we allowed osteolysis to develop until it could be detected by live animal X-ray, then started treatment (post-osteolysis). Although osteolysis in vehicle-treated mice continued, RON inhibition prevented further bone loss (Figure 2A, C; post-osteolysis panels). Again, the number of $\mathrm{TRAP}^{+}$osteoclasts (Figure S6A-B) and bone formation (Figure S6C-E) were not affected by RON inhibitor treatment, supporting an interpretation in which blockade of RON signaling reduces MSPinduced osteoclast activity but does not decrease osteoclast numbers or increase osteoblast activity.

OSI-296, but not BMS-777607/ASLAN002, also significantly reduced tumor growth in the bone (Figure S7A-C). These data suggest that certain RON/MET inhibitors may block tumor growth in addition to preventing osteolysis, although we speculate that the effect of OSI-296 on tumor growth might be due to the decreased specificity of OSI-296 as compared to BMS-777607/ASLAN002 $(28,29)$ (see discussion). These data also indicate that the strong inhibition of osteolysis by BMS-777607/ASLAN002 cannot be explained by an effect on tumor growth, as BMS-777607/ASLAN002 was more effective than OSI-296 in blocking osteolysis but less effective than OSI-296 in reducing tumor growth.

\section{MSP/RON signaling activates osteolysis independent of RANKL or TGF $\beta$ signaling}

As discussed above, both RANKL and TGF $\beta$ play major roles in osteoclast activation and the vicious cycle of tumor-bone interaction. Denosumab, a RANKL antagonist, is FDAapproved to treat bone metastasis and osteoporosis on the basis of its ability to decrease the development of skeletal-related events, such as fracture, in patients $(10,30,31)$. In mice, RON inhibition did not affect RANKL levels in the serum, suggesting that decreased osteolysis in $\mathrm{RON} \mathrm{TK}^{-/-}$mice was not simply a result of a reduction in RANKL (Figure 3A). To directly test whether MSP-driven osteolysis is dependent on the RANKL pathway, we treated mice with the murine RANKL antagonist, muRANK-Fc, beginning three days after injection of tumor cells. The efficacy of muRANK-Fc treatment was confirmed by a dramatic reduction in TRAP expression (Figure S8A-B). As expected from the existing literature $(32,33)$, muRANK-Fc treatment decreased bone destruction by control PyMT tumors (Figures 3B, S8C), further demonstrating the effectiveness of muRANK-Fc treatment in our assays. Notably, muRANK-Fc treatment did not significantly affect the osteolysis associated with MSP-expressing tumor cells (Figures 3B, S8C). These data 
suggest that, although the RANKL antagonist is effective in our assays, MSP-mediated osteolysis occurs independently of RANKL signaling in the tumor setting in vivo. Furthermore, in this model of MSP-expressing breast cancer, RON inhibitors were more effective than the RANKL antagonist in blocking osteolysis (compare Figures 2A-D and 3B).

To further investigate the hypothesis that MSP/RON stimulates RANKL-independent osteolysis, we utilized another human breast cancer model that was previously shown to be dependent on RANKL for osteolysis (MDA-MB-231). MDA-MB-231 cells do not express endogenous MSP at detectable levels (Figure S9A), and muRANK-Fc treatment was effective at reducing the osteolysis associated with control tumors (Figures 3C, S9B), confirming previous work that RANKL signaling promotes osteolysis associated with MDAMB-231 tumors (32). However, engineered expression of MSP in MDA-MB-231 cells (Figure S9A) led to a significant increase in osteolysis, which was not amenable to treatment with muRANK-Fc (Figures 3C, S9B). In contrast, treatment with OSI-296 blocked MSPmediated osteolysis (Figures 3C, S9B). These data again demonstrate that MSP-mediated osteolysis was not inhibited by RANKL signaling blockade in vivo and that RON inhibition was superior to RANKL inhibition in a second in vivo model.

Although the majority of RANKL that contributes to osteoclast activity is thought to be derived from osteoblasts, some reports have indicated that tumor-derived RANKL can contribute to osteolysis (34-36). We found that RANKL and MSP gene expression do not correlate in human breast tumors (Figure S9C), again suggesting that these two pathways can function independently. Since approximately $40 \%$ of human breast cancers overexpress MSP (22), our data suggest that treatment with a combination of RANKL and RON inhibitors may be more effective than targeting RANK signaling alone (see discussion).

We next investigated whether osteolysis downstream of MSP/RON signaling was dependent on TGF $\beta$ released from osteolytic lesions and acting on tumor cells (6). Although TGF $\beta$ is an integral player in the vicious cycle with RANKL, RANKL-independent mechanisms of TGF $\beta$-mediated osteolysis have been reported (37). We injected TGF $\beta$ type-II receptor (TGF $\beta$ RII)-deficient PyMT tumor cells (38) with and without MSP expression into tibias of WT mice to test whether MSP/RON functionally interacts with the TGF $\beta$ pathway to induce osteoclast activation. Although the absence of TGF $\beta$ signaling in PyMT tumors did not significantly affect tumor growth (Figure S9D), basal levels of osteolysis caused by control tumors were reduced (Figures 3D, S9E). In contrast, MSP-overexpressing tumors caused robust osteolysis even in the absence of TGF $\beta$ RII expression (Figures 3D, S9E). Taken together, this evidence suggests that, although the RANKL-TGF $\beta$ portion of the vicious cycle is active in the PyMT model of bone metastasis in the absence of MSP, the expression of MSP triggers osteolysis through a mechanism that does not strictly depend on RANKL or TGF $\beta$.

\section{MSP/RON signaling stimulates osteoclast activity through RANK-independent SRC phosphorylation}

To investigate how RON activation affects osteoclast function, we stimulated primary osteoclast cultures with recombinant MSP and measured their ability to resorb an artificial 
bone matrix. Addition of MSP to WT osteoclasts caused a significant increase in resorption and had no effect on RON TK${ }^{--}$osteoclasts (Figures 4A and S10A). Of note, osteoclast differentiation appeared unaffected by the absence of functional RON signaling, as RON TK -I- osteoclasts formed normally (Figure S10B). Similar to the results of our in vivo studies, MSP-mediated resorption was significantly reduced upon addition of RON inhibitors BMS-777607/ASLAN002 or OSI-296 to osteoclast cultures (Figure 4B-C). MSP-induced resorption in vitro and subsequent amelioration with RON inhibitor treatment is consistent with osteoclasts being the primary cell type mediating MSP-induced osteolysis in vivo.

In addition to its effect on osteoclast resorption, we also noted that MSP was sufficient to promote an approximately 2-fold increase in survival of mature osteoclasts upon withdrawal of RANKL (Figure S10C-D). MSP-mediated survival was blocked by a small molecule inhibitor of SRC kinases, known signaling mediators in osteoclasts (Figure S10D). To test whether MSP also has a role in osteoclast differentiation, MSP was added to osteoclast precursors at different time points in the absence of RANKL (Figure S10E-F). Although we confirmed the requirement for RANKL for osteoclastogenesis (Figure S10F and blue bars in S10G), we found no evidence that MSP/RON can substitute for RANKL in osteoclast differentiation. Together, these data suggest that RON signaling is distinct from RANK signaling in osteoclasts, as RON does not promote osteoclast differentiation. However, both RON and RANK signaling appear to contribute to osteoclast survival and activity through separate pathways that may converge on SRC kinases.

SRC is known to be critical for osteoclast survival, motility, cytoskeletal reorganization, and bone resorption downstream of RANK (39-41). We tested SRC phosphorylation in the presence or absence of MSP, with and without concomitant RANKL signaling. Addition of MSP to WT osteoclasts increased SRC phosphorylation at Y416, which was blocked by BMS-777607/ASLAN002, but not by muRANK-Fc (Figure 4D). Additionally, SRC phosphorylation at Y527 was also observed after MSP treatment (Figure S10H).

In addition to SRC, osteoclasts in this model express SRC family members FYN, HCK, LYN, and YES (Figure S11A-D). Despite the expression of multiple SRC family members, we sought to determine whether SRC activation could rescue the poor resorptive activity of RON TK ${ }^{-/-}$osteoclasts. RON TK ${ }^{-/}$osteoclast precursors were transduced with WT SRC, constitutively-active SRC, or kinase-dead SRC mutants (42). Expression of WT and kinasedead SRC had no significant effect on osteoclast resorption; however, constitutively active SRC fully rescued resorption in $\mathrm{RON} \mathrm{TK}^{-/-}$osteoclasts (Figure 4E). Increased resorption was a result of increased osteoclast activity, rather than an effect of SRC on survival, as no differences in osteoclast survival were observed in $\mathrm{RON} \mathrm{TK}^{-/}$cultures with constitutive SRC activation in the absence of RANKL (Figure S10G). Although these data do not rule out a role for other SRC family members in osteoclast resorption, they do indicate that SRC activation is sufficient to rescue resorption in $\mathrm{RON} \mathrm{TK}^{-/}$osteoclasts. Altogether, these in vivo and in vitro data support a model in which (1) MSP-expressing bone metastatic tumors activate RON on mature osteoclasts to promote both survival and bone resorption through a pathway separate from and parallel to RANK signaling; and (2) SRC kinase functions downstream of RON to promote osteolysis (Figure 4F). 


\section{Efficacy of RON inhibition in ovariectomy-induced osteoporosis}

Pathways that control tumor-mediated osteolysis are also involved in other kinds of bone destruction. To investigate the role of MSP/RON in bone loss resulting from postmenopausal osteoporosis, we performed ovariectomies in WT and $\mathrm{RON} \mathrm{TK}^{-/}$mice and analyzed bone loss by dual-energy X-ray absorptiometry (DXA) and bone histomorphometry. As above, we observed no basal differences in bone density in WT and RON TK ${ }^{-/}$mice under normal physiologic conditions (sham-operated controls) (Figure 5A-E). After ovariectomy, WT mice displayed evidence of bone loss with significantly lower bone mineral density (BMD) than sham-operated controls; however, $\mathrm{RON} \mathrm{TK}^{-1-}$ mice were protected from bone loss (Figure 5A-E). When WT mice were treated with BMS-777607/ASLAN002, loss of bone mineral density after ovariectomy was completely prevented (Figure 5A-E).

\section{The RON inhibitor BMS-777607/ASLAN002 reduces bone turnover in postmenopausal women}

Our pre-clinical in vivo and in vitro data suggest a role for RON in activating osteoclasts through a pathway parallel to RANK signaling and indicate that RON inhibitors may protect from bone loss. To determine whether our findings are translatable to humans, we asked whether BMS-777607/ASLAN002 could affect bone turnover in human subjects being treated with this drug in the context of a Phase 1 clinical trial in cancer patients (NCT01721148). We reasoned that, regardless of cancer diagnosis and even in the absence of bone metastasis, RON inhibition might affect normal bone turnover, especially in postmenopausal women because of their high rate of bone loss. We examined plasma samples from Phase 1 patients for evidence of bone turnover at baseline and after treatment with BMS-777607/ASLAN002 (Table S1). We utilized a standard clinical test conducted at Associated Regional and University Pathologists, Inc (ARUP) Laboratories, a National Reference Laboratory, to detect cleaved bone-derived collagen in plasma ( $\beta$-cross-linked Ctelopeptide (CTX)). These data showed that 13/21 (62\%) of all subjects exhibited decreased CTX levels after treatment with BMS-777607/ASLAN002 for 15-28 days, and approximately two-thirds of those had a sufficient drop in CTX levels ( $\geq 25 \%$ reduction) to meet the Mayo Clinic guidelines (43) for response to bone anti-resorptive therapies (Figure $6 \mathrm{~A})$.

The best responses were seen in women (Figure 6B), where 9/11 (82\%) women had decreases in CTX levels from baseline and 7/11 women (64\%) showed $225 \%$ decrease (versus $1 / 10$ men). In this analysis, all subjects except one were $>50$ years old; women older than 50 are expected to have the greatest amount of physiologic bone turnover, a result of menopause. None of the patients analyzed were treated concurrently with anti-osteoporotic agents. The decrease in CTX was accompanied by an increase in bone-specific alkaline phosphatase (BSAP) levels, a marker of osteoblast activity, suggesting bone repair (Figure 6C-D). It is important to note that these patients were not selected because of a diagnosis of bone metastasis; rather, we simply assessed markers of bone turnover in patients with various cancer diagnoses who participated in the Phase 1 trial of BMS-777607/ASLAN002. These correlative data, when considered together with our pre-clinical data from animal models and in vitro, indicate that inhibition of RON reduces osteoclast activity. These results 
provide a rationale for continued investigation of the use of RON inhibitors to treat bone destructive diseases such as osteolytic bone metastasis and osteoporosis.

\section{Discussion}

Here, we identify RON signaling as a likely target for the treatment of pathogenic bone loss in the settings of breast cancer metastasis and osteoporosis. Using in vivo metastasis models and in vitro osteoclast assays, we demonstrate that MSP/RON signaling promotes osteoclast activation, but not differentiation. This work demonstrates the potential for therapeutically targeting the RON pathway, as two RON inhibitors blocked bone destruction in pre-clinical mouse models of bone metastasis and osteoporosis. One of the inhibitors, BMS-777607/ ASLAN002, is currently being tested in humans as an anti-cancer agent. In Phase 1 testing, BMS-777607/ASLAN002 was safe and well-tolerated by patients (44). These patients showed significant improvement in bone turnover markers after 15-28 days of treatment with BMS-777607/ASLAN002, particularly post-menopausal women. Although uninformative about the effects of BMS-777607/ASLAN002 on cancer progression, these data provide support for a role of RON in bone turnover in humans. Thus, future clinical trials to directly examine the effect of BMS-777607/ASLAN002 on bone health are warranted.

RON expression in differentiated osteoclasts and the dramatic increase in RONmRNA expression as pre-osteoclasts differentiate into osteoclasts in vitro have previously been demonstrated $(17,18)$ along with the ability of MSP to stimulate osteoclast activity in vitro $(16,21)$. Our data now show how MSP/RON signaling promotes osteoclast activity, and that RON functions in osteoclasts in vivo. In addition to demonstrating a role for RON in MSPinduced osteolysis in models of breast cancer bone metastasis, our data reveal a role for RON in osteoporosis. Although how RON signaling leads to increased osteolysis in ovariectomized animals is unknown, possible explanations that warrant further investigation include increasing levels of active MSP after ovarian hormone withdrawal or increasing sensitivity of osteoclasts to MSP through upregulation of RON.

Our in vivo and in vitro data collectively show that RON activation by MSP stimulates survival and bone resorption in mature osteoclasts through activation of SRC signaling, even in the absence of functional RANKL. We observed increased phosphorylation of SRC at both the activating site (Y416) and the inactivating site (Y527). Induction of SRC phosphorylation at both tyrosine phosphorylation sites, as well as activated SRC signaling in the absence of reduced phosphorylation at Y527, has been observed by others (45-47), and likely reflects heterogeneity among the cells. In our studies the dominant functional effect of RON was an overall increase in SRC activity, evidenced by a decrease in downstream SRC signaling after RON inhibition, and our observation that constitutively-activated SRC rescued resorption in osteoclasts lacking RON kinase activity. Whether RON kinase activity in osteoclasts activates SRC through direct phosphorylation or indirectly through CSK or the regulation of additional kinases remains to be determined. SRC is responsible for several critical functions in osteoclasts, including cytoskeletal reorganization and ruffled border formation, thereby regulating the ability of osteoclasts to resorb bone (40). Deletion of SRC in mice leads to severe osteopetrosis, despite the presence of mature osteoclasts, indicating 
that the disease develops due to a defect in osteoclast function and not a lack of differentiation (39). Similarly, RON TK ${ }^{-/}$mice contain normal numbers of osteoclasts and normal bone mineral density, but have defective osteoclast function under disease conditions. This points toward the MSP/RON pathway having a role in the activation of mature osteoclasts, without affecting differentiation, and distinguishes the MSP/RON pathway from others such as RANKL that execute a combined effect on both differentiation and activity. Our in vitro studies confirmed that osteoclasts can also express the SRC family members FYN, HCK, LYN, and YES (48-53). Similar to SRC, HCK and FYN positively regulate osteoclast function $(49,51)$, while LYN negatively regulates osteoclastogenesis (52, 53). To our knowledge, a specific role for YES in osteoclast differentiation/function has not been previously described. Although constitutively active SRC fully rescued resorption in RON TK ${ }^{-1}$ osteoclasts, the phospho-SRC antibodies used in our studies do not discriminate among SRC family members and we cannot rule out contribution of the other SRC family kinases. Thus, future work will be directed toward further understanding the signaling mechanisms downstream of RON in osteoclasts and how RON activation leads to increased osteoclast resorption.

While we propose a model in which MSP-induced osteolysis occurs downstream of RON activation on osteoclasts independent of RANK signaling, neither our in vivo preclinical studies utilizing whole body deletion of RON tyrosine kinase activity in mice nor our human clinical data definitively identify osteoclast RON as the sole mediator of MSP-induced osteolysis. Additionally, while enriched for osteoclasts, the in vitro model used here contains a heterogenous population of cells; therefore, our studies do not rule out the contribution of other cell types known to express RON, such as macrophages. The potential role of these other cell types in MSP-induced osteolysis can be tested in future studies using cell-specific RON knockout models. Furthermore, although the dramatic reduction in the number of $\mathrm{TRAP}^{+}$osteoclasts following muRANK-Fc treatment in vivo suggests that RANK signaling is effectively blocked in these studies, the inhibitor studies do not directly rule out residual RANK activity that could contribute to MSP-mediated osteolysis. The role of RANKL/ RANK signaling can be further evaluated using knockout strategies. Despite the mechanistic questions still remaining, the studies described here identify host RON as a mediator of osteolytic bone disease and demonstrate the potential for RON inhibitors in the treatment of pathologic bone destruction.

Inhibiting the RON pathway can be achieved through pharmacologic inhibition of its tyrosine kinase activity, either directly with small molecule inhibitors or indirectly with ligand-blocking antibodies (54). RON has multiple isoforms that function in a ligandindependent manner, however, which would not be inhibited by ligand-blocking antibodies. Although several small molecule kinase inhibitors are selective for RON, most also inhibit related kinases such as MET. Several of these are being developed as potential anticancer agents and the RON-selective BMS-777607/ASLAN002 compound has just been tested in a Phase 1 clinical trial for metastatic cancer (NCT01721148). Here, we show that two small molecule inhibitors for RON/MET, including BMS-777607/ASLAN002, block osteolysis in several pre-clinical models. The blockade of osteolysis phenocopied our observations in RON TK ${ }^{-/}$mice, indicating that the effect is likely through RON inhibition, rather than through an effect on a related kinase or an off-target effect. In addition to blocking 
osteolysis, OSI-296 also reduced tumor burden, but this effect was not observed with BMS-777607/ASLAN002 or in RON TK ${ }^{-/}$mice. Thus, decreased tumor size in the presence of OSI-296 might be due to inhibition of other kinases, rather than inhibition of RON signaling, as OSI-296 is less specific for RON than BMS-777607/ASLAN002.

For our cancer studies, we focused on breast cancer because it is the most common cause of osteolytic bone metastasis. In fact, MSP is overexpressed in approximately $40 \%$ of breast cancers (22), indicating a substantial number of patients whose tumors potentially stimulate RON in the microenvironment of bone metastasis. Consistent with this, examination of bone reamings from breast cancer patients undergoing surgery to stabilize bones in areas of metastasis revealed positive MSP expression in 4/6 samples containing metastatic tumor cells (Figure S12).

A survey of Oncomine revealed that MSP is not overexpressed in many cancer types but is selectively overexpressed in two other cancers that also cause osteolytic bone metastasis: multiple myeloma (Figure S13A) and lung cancer (Figure S13B). Therefore, RON inhibitors may be useful to treat osteoporosis and bone loss in several forms of cancer. Our data demonstrate in several models that the MSP/RON pathway can promote activation of mature osteoclasts independently of RANKL signaling, indicating that current standard therapies for bone metastasis that target the RANKL pathway may not fully block osteolysis in patients with MSP-overexpressing tumors. Combination treatment with RON inhibitors and other modulators of osteoclast activity, such as denosumab or bisphosphonates, may be more effective than current treatment strategies alone. Additionally, it will be important to test whether MSP expression levels can predict which patients will experience progression of osteolytic metastasis while being treated with denosumab and which patients will respond best to BMS-777607/ASLAN002 treatment. The results from two Phase 1 clinical trials in oncology using RON inhibitors will be informative (NCT01721148 and NCT01119456).

\section{Supplementary Material}

Refer to Web version on PubMed Central for supplementary material.

\section{Acknowledgments}

We thank Harold Moses for the kind gift of the PyMT/TGF $\beta$ II $^{-/}$cells, and Amgen for muRANK-Fc. We are grateful to Mark Albertella, Mark Mulvihill, and Stuart Thompson, all formerly of OSI Pharmaceuticals, for providing OSI-296 and for helpful discussions, Christa DeVette for help with the BSAP ELISA, Dr. Najme Faham for FYN and HCK immunoblots, and Dr. Rachel Factor and Dr. Ken Boucher for helpful guidance regarding Ki67 quantification and statistical analyses, respectively. We are grateful to Dr. Alan Barge (Aslan Pharmaceuticals), Dr. Lisa Horvath (Chris O'Brien Lifehouse cancer treatment center, Sydney, Australia), and Dr. Ben Tran (Walter \& Eliza Hall Institute of Medical Research, Melbourne, Australia) for helpful clinical discussions regarding BMS-777607/ASLAN002 and for providing plasma samples from the Phase 1 trial.

Funding: This work was supported by the Department of Defense Breast Cancer Research Program grants W81XWH0810109 (A.L.W.) and W81XWH1010366 (K.A.), Susan G. Komen Postdoctoral Fellowship PDF16376311 (J.F.), National Cancer Institute of the National Institutes of Health (NCI/NIH) R01CA166422 (A.L.W.), the Oklahoma Medical Research Foundation, the Stephenson Cancer Center at the University of Oklahoma, and the Huntsman Cancer Foundation and the NCI/NIH Award Number P30CA042014 (various shared resources). The content is solely the responsibility of the authors and does not necessarily represent the official views of the NIH. 


\section{References}

1. National Osteoporosis Foundation report. 2002

2. Coleman RE, Lipton A, Roodman GD, Guise TA, Boyce BF, Brufsky AM, Clezardin P, Croucher PI, Gralow JR, Hadji P, Holen I, Mundy GR, Smith MR, Suva LJ. Metastasis and bone loss: advancing treatment and prevention. Cancer Treat Rev. 2010; 36:615-620. [PubMed: 20478658]

3. Coleman RE. Future directions in the treatment and prevention of bone metastases. Am J Clin Oncol. 2002; 25:S32-38. [PubMed: 12562049]

4. Diel IJ, Solomayer EF, Bastert G. Treatment of metastatic bone disease in breast cancer: bisphosphonates. Clin Breast Cancer. 2000; 1:43-51. [PubMed: 11899389]

5. Melton LJ 3rd, Kyle RA, Achenbach SJ, Oberg AL, Rajkumar SV. Fracture risk with multiple myeloma: a population-based study. J Bone Miner Res. 2005; 20:487-493. [PubMed: 15746994]

6. Guise TA, Mundy GR. Cancer and bone. Endocr Rev. 1998; 19:18-54. [PubMed: 9494779]

7. Weilbaecher KN, Guise TA, McCauley LK. Cancer to bone: a fatal attraction. Nat Rev Cancer. 2011; 11:411-425. [PubMed: 21593787]

8. Gralow JR, Biermann JS, Farooki A, Fornier MN, Gagel RF, Kumar RN, Shapiro CL, Shields A, Smith MR, Srinivas S, Van Poznak CH. NCCN Task Force Report: Bone Health in Cancer Care. J Natl Compr Canc Netw. 2009; 7(Suppl 3):S1-32. quiz S33-35.

9. Lipton A, Fizazi K, Stopeck AT, Henry DH, Brown JE, Yardley DA, Richardson GE, Siena S, Maroto P, Clemens M, Bilynskyy B, Charu V, Beuzeboc P, Rader M, Viniegra M, Saad F, Ke C, Braun A, Jun S. Superiority of denosumab to zoledronic acid for prevention of skeletal-related events: a combined analysis of 3 pivotal, randomised, phase 3 trials. Eur J Cancer. 2012; 48:30823092. [PubMed: 22975218]

10. Stopeck AT, Lipton A, Body JJ, Steger GG, Tonkin K, de Boer RH, Lichinitser M, Fujiwara Y, Yardley DA, Viniegra M, Fan M, Jiang Q, Dansey R, Jun S, Braun A. Denosumab compared with zoledronic acid for the treatment of bone metastases in patients with advanced breast cancer: a randomized, double-blind study. J Clin Oncol. 2010; 28:5132-5139. [PubMed: 21060033]

11. Kurata T, Nakagawa K. Efficacy and safety of denosumab for the treatment of bone metastases in patients with advanced cancer. Jpn J Clin Oncol. 2012; 42:663-669. [PubMed: 22701037]

12. Hageman K, Patel KC, Mace K, Cooper MR. The role of denosumab for prevention of skeletalrelated complications in multiple myeloma. Ann Pharmacother. 2013; 47:1069-1074. [PubMed: 23780806]

13. Coleman RE, Lipton A, Costa L, Cook RJ, Lee KA, Saad F, Brown JE, Terpos E, Major PP, Kohno $\mathrm{N}$, Smith M, Body JJ. Possible survival benefits from zoledronic acid treatment in patients with bone metastases from solid tumours and poor prognostic features-An exploratory analysis of placebo-controlled trials. J Bone Oncol. 2013; 2:70-76. [PubMed: 26909273]

14. Waning DL, Mohammad KS, Reiken S, Xie W, Andersson DC, John S, Chiechi A, Wright LE, Umanskaya A, Niewolna M, Trivedi T, Charkhzarrin S, Khatiwada P, Wronska A, Haynes A, Benassi MS, Witzmann FA, Zhen G, Wang X, Cao X, Roodman GD, Marks AR, Guise TA. Excess TGF-beta mediates muscle weakness associated with bone metastases in mice. Nat Med. 2015; 21:1262-1271. [PubMed: 26457758]

15. Wang MH, Iwama A, Skeel A, Suda T, Leonard EJ. The murine stk gene product, a transmembrane protein tyrosine kinase, is a receptor for macrophage-stimulating protein. Proc Natl Acad Sci U S A. 1995; 92:3933-3937. [PubMed: 7732008]

16. Kurihara N, Tatsumi J, Arai F, Iwama A, Suda T. Macrophage-stimulating protein (MSP) and its receptor, RON, stimulate human osteoclast activity but not proliferation: effect of MSP distinct from that of hepatocyte growth factor. Exp Hematol. 1998; 26:1080-1085. [PubMed: 9766449]

17. Yang G, Zaidi M, Zhang W, Zhu LL, Li J, Iqbal J, Varbanov A, Gross G, Phipps R, Troen BR, Sun L. Functional grouping of osteoclast genes revealed through microarray analysis. Biochem Biophys Res Commun. 2008; 366:352-359. [PubMed: 18060857]

18. Akiyama M, Nakahama K, Morita I. Impact of docosahexaenoic acid on gene expression during osteoclastogenesis in vitro--a comprehensive analysis. Nutrients. 2013; 5:3151-3162. [PubMed: 23945674] 
19. Gaudino G, Avantaggiato V, Follenzi A, Acampora D, Simeone A, Comoglio PM. The protooncogene RON is involved in development of epithelial, bone and neuro-endocrine tissues. Oncogene. 1995; 11:2627-2637. [PubMed: 8545120]

20. Suda T, Iwama A, Hashiyama M, Sakano S, Ohno M. Receptor tyrosine kinases involved in hematopoietic progenitor cells. Leukemia. 1997; 11(Suppl 3):451-453.

21. Kurihara N, Iwama A, Tatsumi J, Ikeda K, Suda T. Macrophage-stimulating protein activates STK receptor tyrosine kinase on osteoclasts and facilitates bone resorption by osteoclast-like cells. Blood. 1996; 87:3704-3710. [PubMed: 8611695]

22. Welm AL, Sneddon JB, Taylor C, Nuyten DSA, van de Vijver MA, Hasegawa BH, Bishop J Michael. The macrophage stimulating protein pathway promotes metastasis in a mouse model for breast cancer and predicts poor prognosis in humans. Proc Natl Acad Sci U S A. 2007; 104:75707575. [PubMed: 17456594]

23. Zinser GM, Leonis MA, Toney K, Pathrose P, Thobe M, Kader SA, Peace BE, Beauman SR, Collins MH, Waltz SE. Mammary-specific Ron receptor overexpression induces highly metastatic mammary tumors associated with beta-catenin activation. Cancer Res. 2006; 66:11967-11974. [PubMed: 17178895]

24. Waltz SE, Eaton L, Toney-Earley K, Hess KA, Peace BE, Ihlendorf JR, Wang MH, Kaestner KH, Degen SJ. Ron-mediated cytoplasmic signaling is dispensable for viability but is required to limit inflammatory responses. J Clin Invest. 2001; 108:567-576. [PubMed: 11518730]

25. Eyob H, Ekiz HA, Derose YS, Waltz SE, Williams MA, Welm AL. Inhibition of ron kinase blocks conversion of micrometastases to overt metastases by boosting antitumor immunity. Cancer Discov. 2013; 3:751-760. [PubMed: 23612011]

26. Takayanagi H. New developments in osteoimmunology. Nat Rev Rheumatol. 2012; 8:684-689. [PubMed: 23070645]

27. Correll PH, Iwama A, Tondat S, Mayrhofer G, Suda T, Bernstein A. Deregulated inflammatory response in mice lacking the STK/RON receptor tyrosine kinase. Genes Funct. 1997; 1:69-83. [PubMed: 9680329]

28. Steinig AG, Li AH, Wang J, Chen X, Dong H, Ferraro C, Jin M, Kadalbajoo M, Kleinberg A, Stolz KM, Tavares-Greco PA, Wang T, Albertella MR, Peng Y, Crew L, Kahler J, Kan J, Schulz R, Cooke A, Bittner M, Turton RW, Franklin M, Gokhale P, Landfair D, Mantis C, Workman J, Wild R, Pachter J, Epstein D, Mulvihill MJ. Novel 6-aminofuro[3,2-c]pyridines as potent, orally efficacious inhibitors of cMET and RON kinases. Bioorg Med Chem Lett. 2013; 23:4381-4387. [PubMed: 23773865]

29. Schroeder GM, An Y, Cai ZW, Chen XT, Clark C, Cornelius LA, Dai J, Gullo-Brown J, Gupta A, Henley B, Hunt JT, Jeyaseelan R, Kamath A, Kim K, Lippy J, Lombardo LJ, Manne V, Oppenheimer S, Sack JS, Schmidt RJ, Shen G, Stefanski K, Tokarski JS, Trainor GL, Wautlet BS, Wei D, Williams DK, Zhang Y, Zhang Y, Fargnoli J, Borzilleri RM. Discovery of N-(4-(2amino-3-chloropyridin-4-yloxy)-3-fluorophenyl)-4-ethoxy-1-(4-fluorophenyl)-2-oxo-1,2dihydropyridine-3-carboxamide (BMS-777607), a selective and orally efficacious inhibitor of the Met kinase superfamily. J Med Chem. 2009; 52:1251-1254. [PubMed: 19260711]

30. Cummings SR, San Martin J, McClung MR, Siris ES, Eastell R, Reid IR, Delmas P, Zoog HB, Austin M, Wang A, Kutilek S, Adami S, Zanchetta J, Libanati C, Siddhanti S, Christiansen C, Trial F. Denosumab for prevention of fractures in postmenopausal women with osteoporosis. N Engl J Med. 2009; 361:756-765. [PubMed: 19671655]

31. Papapoulos S, Chapurlat R, Libanati C, Brandi ML, Brown JP, Czerwinski E, Krieg MA, Man Z, Mellstrom D, Radominski SC, Reginster JY, Resch H, Roman Ivorra JA, Roux C, Vittinghoff E, Austin M, Daizadeh N, Bradley MN, Grauer A, Cummings SR, Bone HG. Five years of denosumab exposure in women with postmenopausal osteoporosis: results from the first two years of the FREEDOM extension. J Bone Miner Res. 2012; 27:694-701. [PubMed: 22113951]

32. Canon JR, Roudier M, Bryant R, Morony S, Stolina M, Kostenuik PJ, Dougall WC. Inhibition of RANKL blocks skeletal tumor progression and improves survival in a mouse model of breast cancer bone metastasis. Clin Exp Metastasis. 2008; 25:119-129. [PubMed: 18064531]

33. Holland PM, Miller R, Jones J, Douangpanya H, Piasecki J, Roudier M, Dougall WC. Combined therapy with the RANKL inhibitor RANK-Fc and rhApo2L/TRAIL/dulanermin reduces bone 
lesions and skeletal tumor burden in a model of breast cancer skeletal metastasis. Cancer Biol Ther. 2010; 9:539-550. [PubMed: 20150760]

34. Azim HA Jr, Michiels S, Bedard PL, Singhal SK, Criscitiello C, Ignatiadis M, Haibe-Kains B, Piccart MJ, Sotiriou C, Loi S. Elucidating prognosis and biology of breast cancer arising in young women using gene expression profiling. Clin Cancer Res. 2012; 18:1341-1351. [PubMed: 22261811]

35. Azim HA Jr, Peccatori FA, Brohee S, Branstetter D, Loi S, Viale G, Piccart M, Dougall WC, Pruneri G, Sotiriou C. RANK-ligand (RANKL) expression in young breast cancer patients and during pregnancy. Breast Cancer Res. 2015; 17:24. [PubMed: 25849336]

36. Huang L, Cheng YY, Chow LT, Zheng MH, Kumta SM. Tumour cells produce receptor activator of NF-kappaB ligand (RANKL) in skeletal metastases. J Clin Pathol. 2002; 55:877-878. [PubMed: 12401833]

37. Sethi N, Dai X, Winter CG, Kang Y. Tumor-derived JAGGED1 promotes osteolytic bone metastasis of breast cancer by engaging notch signaling in bone cells. Cancer Cell. 2011; 19:192205. [PubMed: 21295524]

38. Forrester E, Chytil A, Bierie B, Aakre M, Gorska AE, Sharif-Afshar AR, Muller WJ, Moses HL. Effect of conditional knockout of the type II TGF-beta receptor gene in mammary epithelia on mammary gland development and polyomavirus middle $\mathrm{T}$ antigen induced tumor formation and metastasis. Cancer Res. 2005; 65:2296-2302. [PubMed: 15781643]

39. Soriano P, Montgomery C, Geske R, Bradley A. Targeted disruption of the c-src proto-oncogene leads to osteopetrosis in mice. Cell. 1991; 64:693-702. [PubMed: 1997203]

40. Boyce BF, Yoneda T, Lowe C, Soriano P, Mundy GR. Requirement of pp60c-src expression for osteoclasts to form ruffled borders and resorb bone in mice. J Clin Invest. 1992; 90:1622-1627. [PubMed: 1383278]

41. Izawa T, Zou W, Chappel JC, Ashley JW, Feng X, Teitelbaum SL. c-Src links a RANK/ alphavbeta3 integrin complex to the osteoclast cytoskeleton. Mol Cell Biol. 2012; 32:2943-2953. [PubMed: 22615494]

42. Lin PH, Shenoy S, Galitski T, Shalloway D. Transformation of mouse cells by wild-type mouse cSrc. Oncogene. 1995; 10:401-405. [PubMed: 7530829]

43. Mayo Clinic Medical Laboratories. Beta-CrossLaps (Beta-CTx). Serum. http:// www.mayomedicallaboratories.com/test-catalog/Clinical+and+Interpretive/83175

44. Aslan Pharmaceuticals, (2016).

45. Moiseeva EP, Heukers R, Manson MM. EGFR and Src are involved in indole-3-carbinol-induced death and cell cycle arrest of human breast cancer cells. Carcinogenesis. 2007; 28:435-445. [PubMed: 16956907]

46. Mainou BA, Dermody TS. Src kinase mediates productive endocytic sorting of reovirus during cell entry. J Virol. 2011; 85:3203-3213. [PubMed: 21248042]

47. Moon HG, Qin Z, Quan T, Xie L, Dela Cruz CS, Jin Y. Matrix protein CCN1 induced by bacterial DNA and CpG ODN limits lung inflammation and contributes to innate immune homeostasis. Mucosal Immunol. 2015; 8:243-253. [PubMed: 25005359]

48. Kabos P, Finlay-Schultz J, Li C, Kline E, Finlayson C, Wisell J, Manuel CA, Edgerton SM, Harrell JC, Elias A, Sartorius CA. Patient-derived luminal breast cancer xenografts retain hormone receptor heterogeneity and help define unique estrogen-dependent gene signatures. Breast Cancer Res Treat. 2012; 135:415-432. [PubMed: 22821401]

49. Kim HJ, Warren JT, Kim SY, Chappel JC, DeSelm CJ, Ross FP, Zou W, Teitelbaum SL. Fyn promotes proliferation, differentiation, survival and function of osteoclast lineage cells. J Cell Biochem. 2010; 111:1107-1113. [PubMed: 20717919]

50. Horne WC, Neff L, Chatterjee D, Lomri A, Levy JB, Baron R. Osteoclasts express high levels of pp60c-src in association with intracellular membranes. J Cell Biol. 1992; 119:1003-1013. [PubMed: 1385441]

51. Verollet C, Gallois A, Dacquin R, Lastrucci C, Pandruvada SN, Ortega N, Poincloux R, Behar A, Cougoule C, Lowell C, Al Saati T, Jurdic P, Maridonneau-Parini I. Hck contributes to bone homeostasis by controlling the recruitment of osteoclast precursors. FASEB J. 2013; 27:36083618. [PubMed: 23742809] 
52. Kim HJ, Zhang K, Zhang L, Ross FP, Teitelbaum SL, Faccio R. The Src family kinase, Lyn, suppresses osteoclastogenesis in vitro and in vivo. Proc Natl Acad Sci U S A. 2009; 106:23252330. [PubMed: 19171907]

53. Yoon SH, Lee Y, Kim HJ, Lee ZH, Hyung SW, Lee SW, Kim HH. Lyn inhibits osteoclast differentiation by interfering with PLCgamma1-mediated Ca2+ signaling. FEBS Lett. 2009; 583:1164-1170. [PubMed: 19285079]

54. Kretschmann KL, Eyob H, Buys SS, Welm AL. The macrophage stimulating protein/Ron pathway as a potential therapeutic target to impede multiple mechanisms involved in breast cancer progression. Curr Drug Targets. 2010; 11:1157-1168. [PubMed: 20545605]

55. Parfitt AM, Drezner MK, Glorieux FH, Kanis JA, Malluche H, Meunier PJ, Ott SM, Recker RR. Bone histomorphometry: standardization of nomenclature, symbols, and units. Report of the ASBMR Histomorphometry Nomenclature Committee. J Bone Miner Res. 1987; 2:595-610. [PubMed: 3455637] 


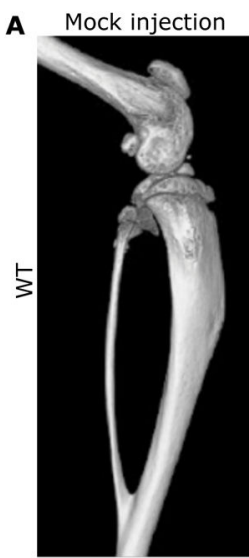

Control cells MSP cells
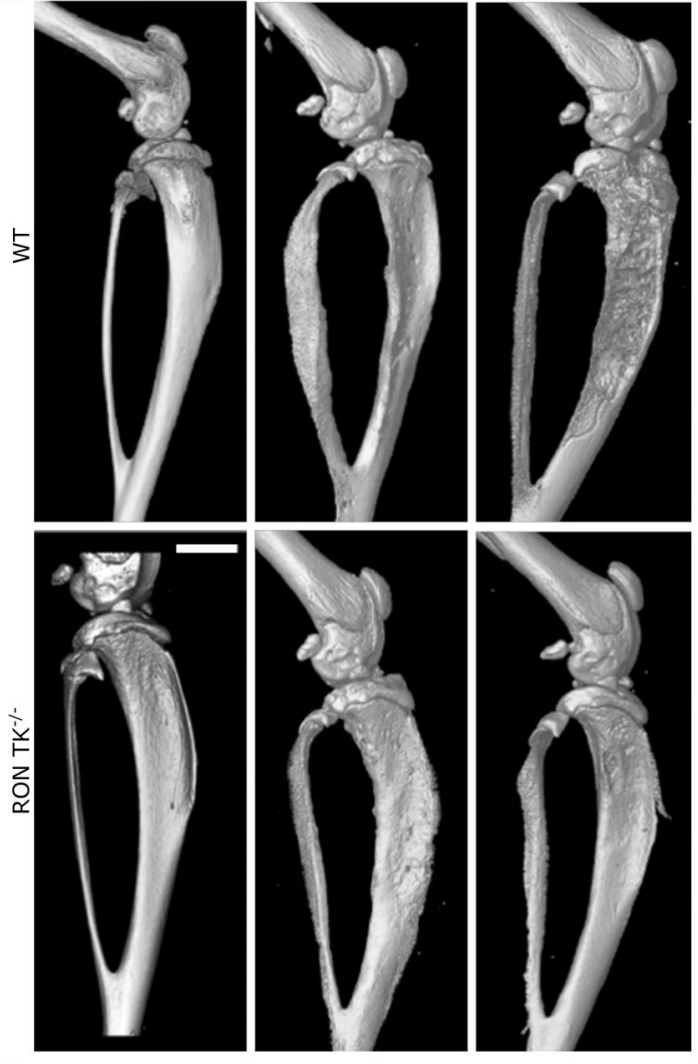

B

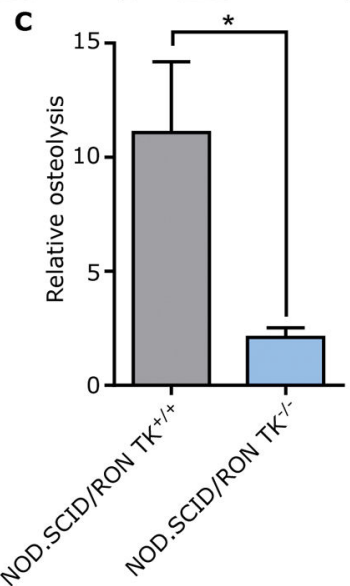

Fig. 1. MSP induction of bone osteolysis requires host RON kinase activity

(A) Representative microcomputed tomography $(\mu \mathrm{CT})$ images of tibial bone lesions, 21 days after PyMT tumor cell injection. Scale bar, $2 \mathrm{~mm}$. (B) Quantification of osteolytic area in tibias 42 days after PyMT-MSP tumor cell injection using high resolution ex vivo X-ray analysis ( $\mathrm{n}=10$ per group); $* * \mathrm{p}=0.0013, * * * \mathrm{p}=0.0001, \mathrm{~ns}=$ not significant, two-tailed, unpaired Welch's t-tests. (C) Quantification of osteolytic area in tibias 35 days after DU4475 tumor cell injection using high resolution ex vivo $\mathrm{X}$-ray analysis ( $\mathrm{n}=5$ per group); $*_{\mathrm{p}}=0.021$, two-tailed, unpaired Welch's t-test. 
A

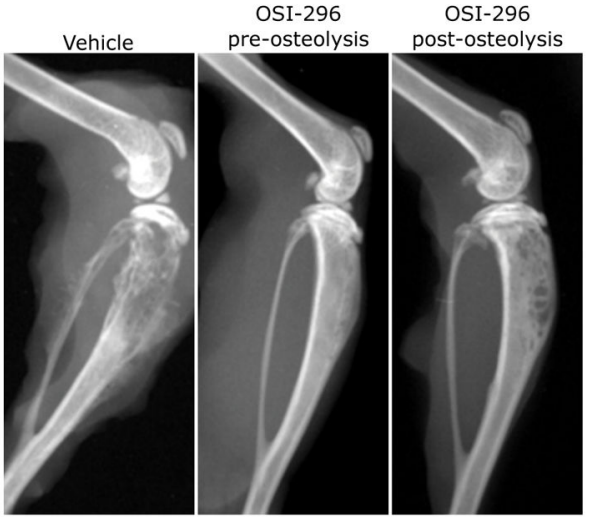

PYMT-MSP tumor cells

B

BMS-777607/ASLAN002

B Vehicle pre-osteolysis

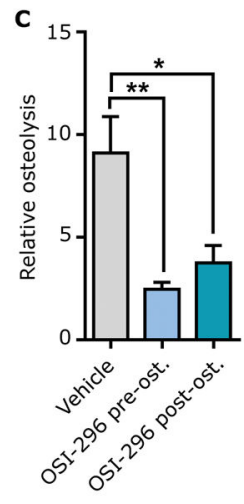

PyMT-MSP tumor cells

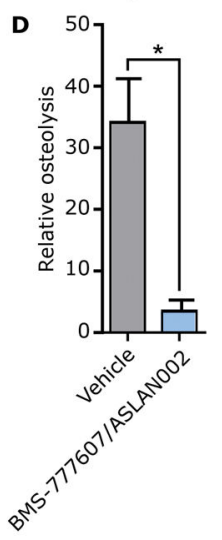

E

vehicle

BMS-777607/ASLAN002
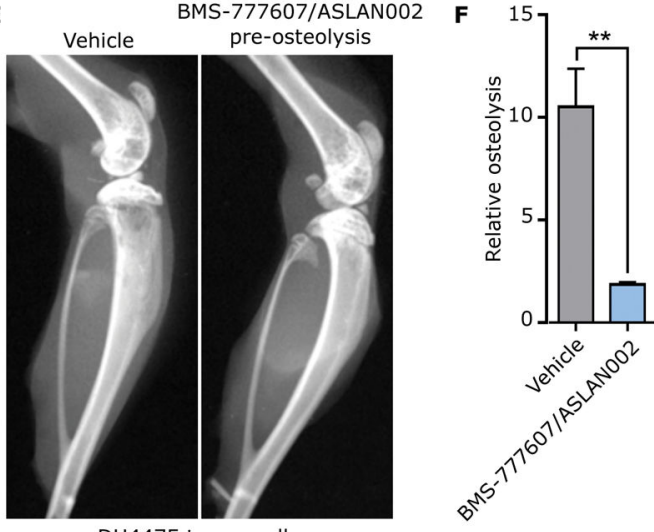

DU4475 tumor cells

Fig. 2. RON inhibition reduces osteolysis in prophylactic and therapeutic settings

(A) Representative X-rays of PyMT-MSP bone lesions from mice treated with OSI-296.

Treatment began 3 days after tumor cell injection (pre-osteolysis) or 3 weeks after injection (post-osteolysis). Mice were sacrificed 42 days after injection for analysis. (B)

Representative X-rays of PyMT-MSP bone lesions from mice treated with BMS-777607/

ASLAN002. Treatment began 3 days after tumor cell injection. Mice were sacrificed 21 days after injection for analysis. (C) Quantification of osteolytic area in PyMT-MSP bone lesions from mice treated with OSI-296 pre- or post-osteolysis ( $\mathrm{n}=5-9$ per group); ${ }^{\mathrm{p}} \mathrm{p}=0.024$, ** $\mathrm{p}=0.0091$, two-tailed, unpaired Welch's t-tests. (D) Quantification of osteolytic area in 
PyMT-MSP bone lesions from mice treated with BMS-777607/ASLAN002 ( $\mathrm{n}=4-5$ per group); ${ }^{\mathrm{p}}=0.011$, two-tailed, unpaired Welch's t-test $(\mathbf{E})$ Representative X-rays of DU4475-induced bone lesions from mice treated with BMS-777607/ASLAN002. Treatment began 3 days after tumor cell injection. Mice were sacrificed 28 days after injection for analysis. (F) Quantification of osteolytic area in DU4475 bone lesions from mice treated with BMS-777607/ASLAN002 ( $\mathrm{n}=5$ per group); ${ }^{* *} \mathrm{p}=0.0094$, two-tailed, unpaired Welch's t-test. 

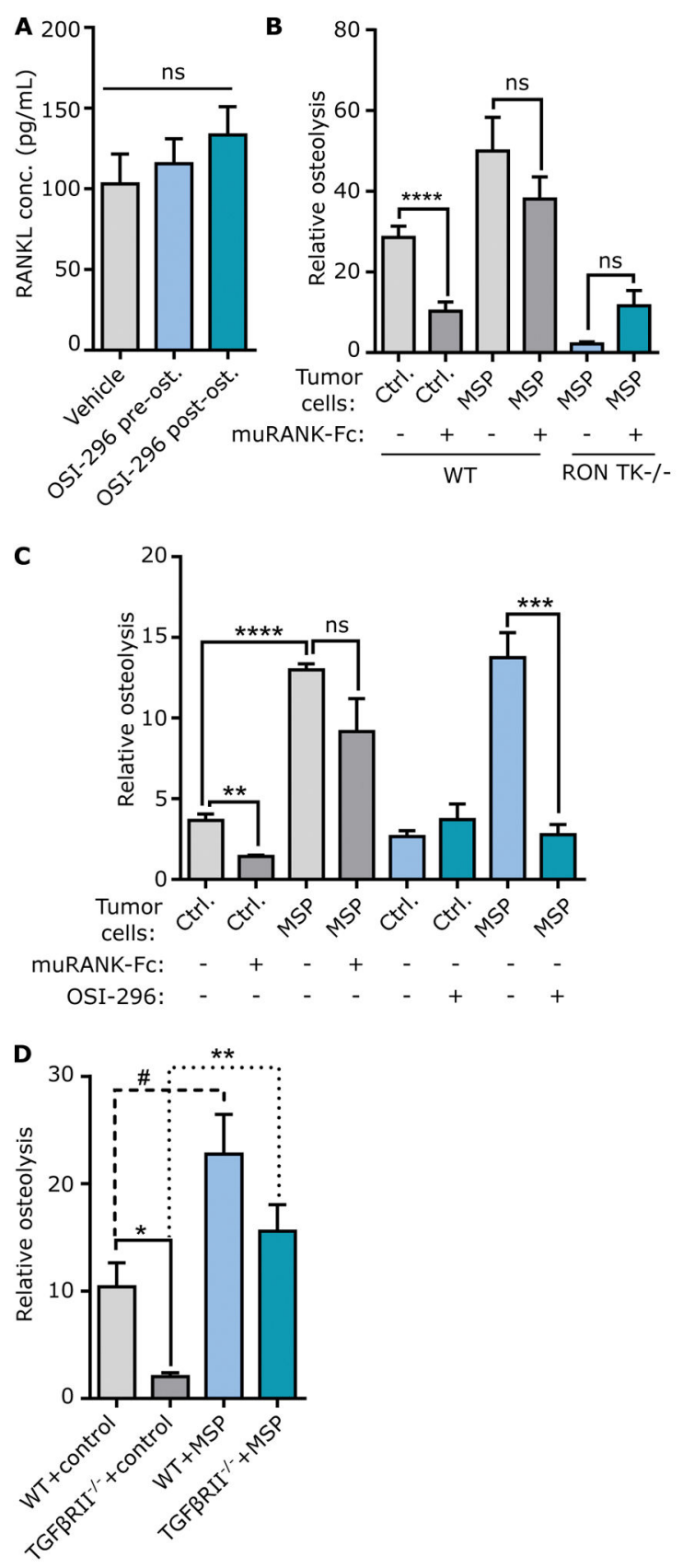

Fig. 3. MSP tumor-induced osteolysis does not depend on RANKL or TGF $\beta$ signaling

(A) Serum RANKL concentration in mice ( $\mathrm{n}=3$ per group); $n s=$ not significant, two-tailed, unpaired Welch's t-test. (B) Quantification of osteolytic area in bone lesions from mice $(\mathrm{n}=11-16$ per group for WT mice and $\mathrm{n}=3(-$ muRANK-Fc) or $5(+$ mu-RANK-Fc) per group for RON TK ${ }^{-/-}$mice); ****p<0.0001, two-tailed, unpaired Welch's t-test. (C) Quantification of osteolytic area in mice with MDA-MB-231 tumors ( $n=4-7$ per group). Mice were treated with either mu-RANK-Fc or OSI-296 beginning 3 days after tumor cell injection and throughout the experiment; $* * \mathrm{p}=0.0094$, $* * * \mathrm{p}=0.0004, * * * * \mathrm{p}<0.0001$, twotailed, unpaired Welch's t-tests. (D) Quantification of osteolytic area in mice injected with 
WT PyMT tumors +/- MSP expression or TGF $\beta \mathrm{RII}^{-/-}$PyMT tumors +/- MSP expression ( $\mathrm{n}=5-6$ per group); ${ }^{*} \mathrm{p}=0.027,{ }^{*} \mathrm{p}=0.032,{ }^{*} \mathrm{p}=0.0050$, two-tailed, unpaired Welch's t-tests. 

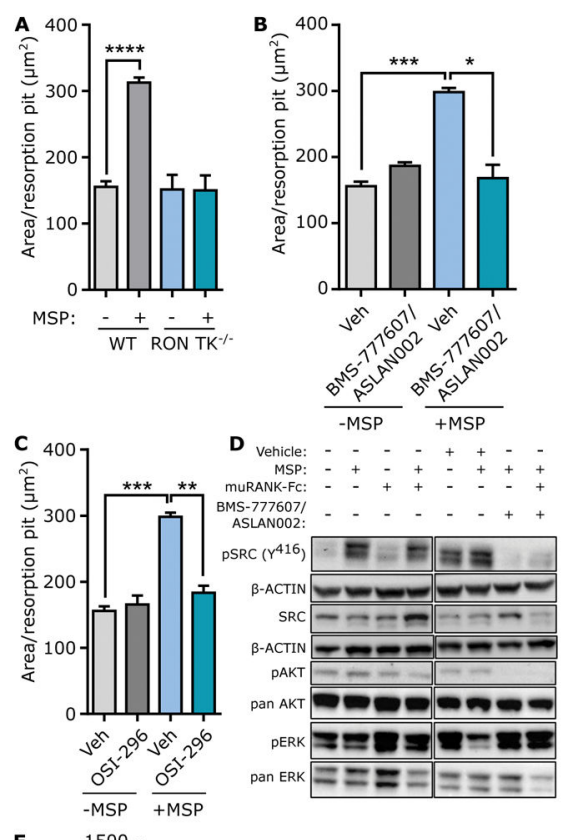

E
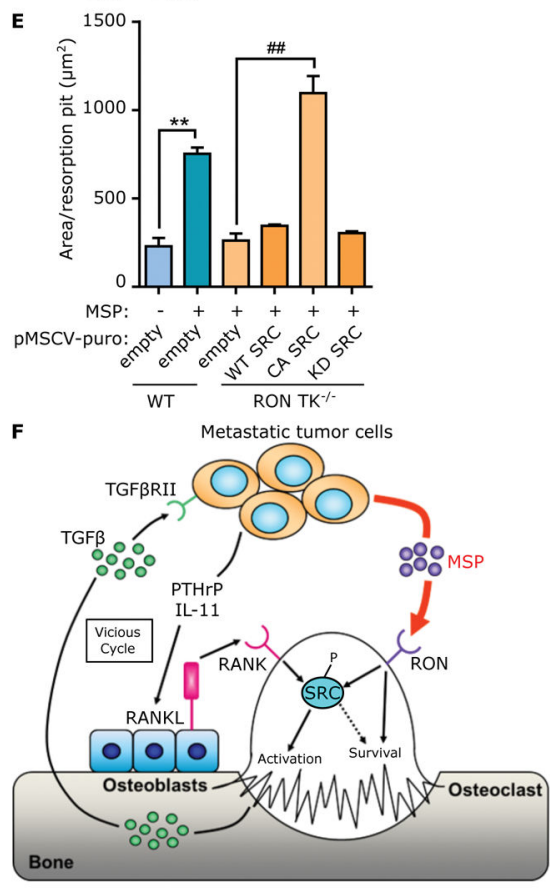

Fig. 4. MSP promotes osteoclast activity and survival through activation of SRC

(A) In vitro resorption area of WT or RON TK${ }^{-/}$osteoclasts +/- MSP (n=4 per group); ****p $<0.0001$, two-tailed, unpaired Welch's t-test. (B-C) Quantification of resorption area +/- MSP and/or the RON inhibitors BMS-777607/ASLAN002 (B) or OSI-296 (C); n=3 per group; * $\mathrm{p}=0.016,{ }^{*} \mathrm{p}=0.0020, * * \mathrm{p}=0.0001$, two-tailed, unpaired Welch's t-tests. (D) Representative Western blots of osteoclast lysates from WT cells treated with MSP, muRANK-Fc, and/or BMS-777607/ASLAN002. (E) Quantification of resorption area from RON TK ${ }^{-1-}$ bone marrow precursor cells transduced with empty vector, WT, constitutively active (CA), or kinase dead (KD) SRC, +/- MSP. WT osteoclasts served as a control for 
normal osteoclast activity ( $\mathrm{n}=3$ per group). ${ }^{* *} \mathrm{p}=0.0013,{ }^{\# \#} \mathrm{p}=0.0060$, two-tailed, unpaired Welch's t-tests. (F) Model of signaling pathways in the bone microenvironment that control MSP-mediated osteolysis. We propose that MSP/RON signaling functions in parallel to the vicious cycle mediated by RANKL and TGF $\beta$. 
A
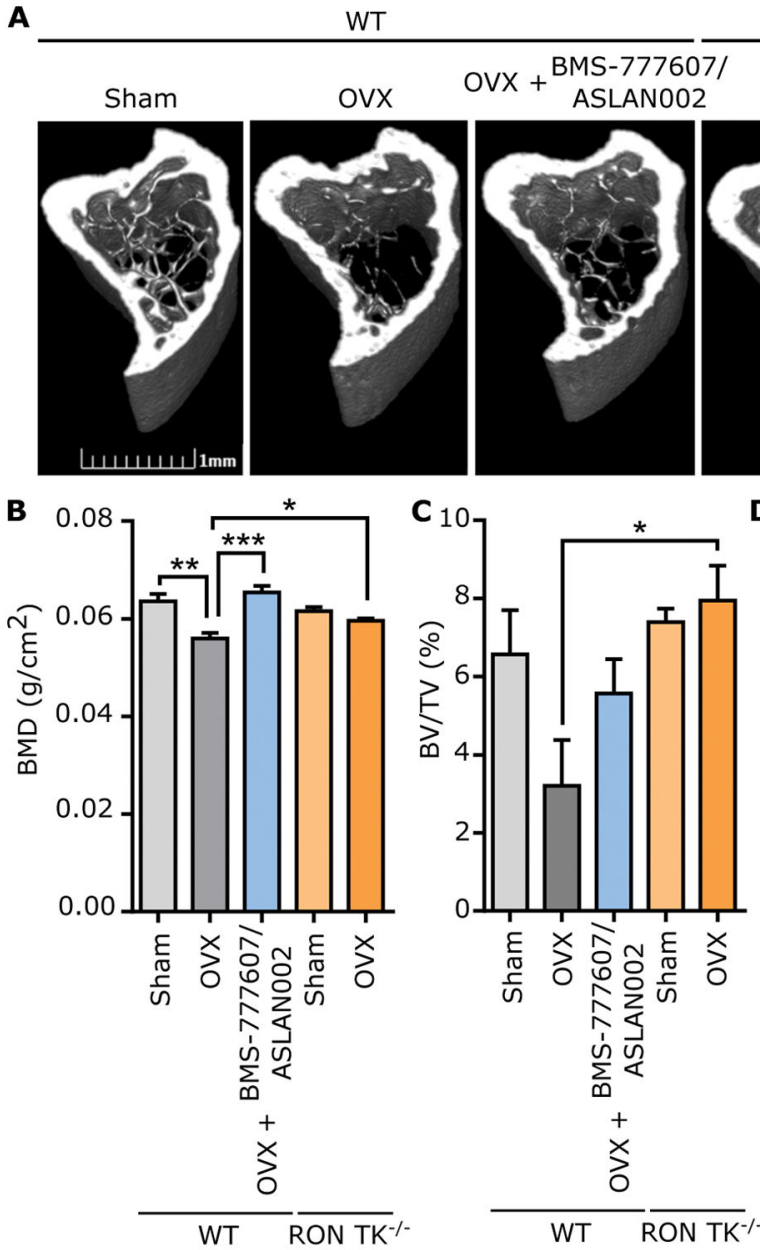

RON $\mathrm{TK}^{-/-}$

E

WT
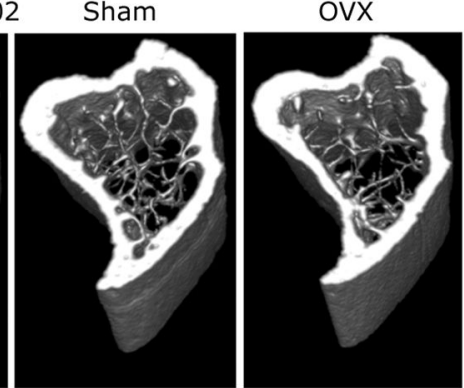

D 50007
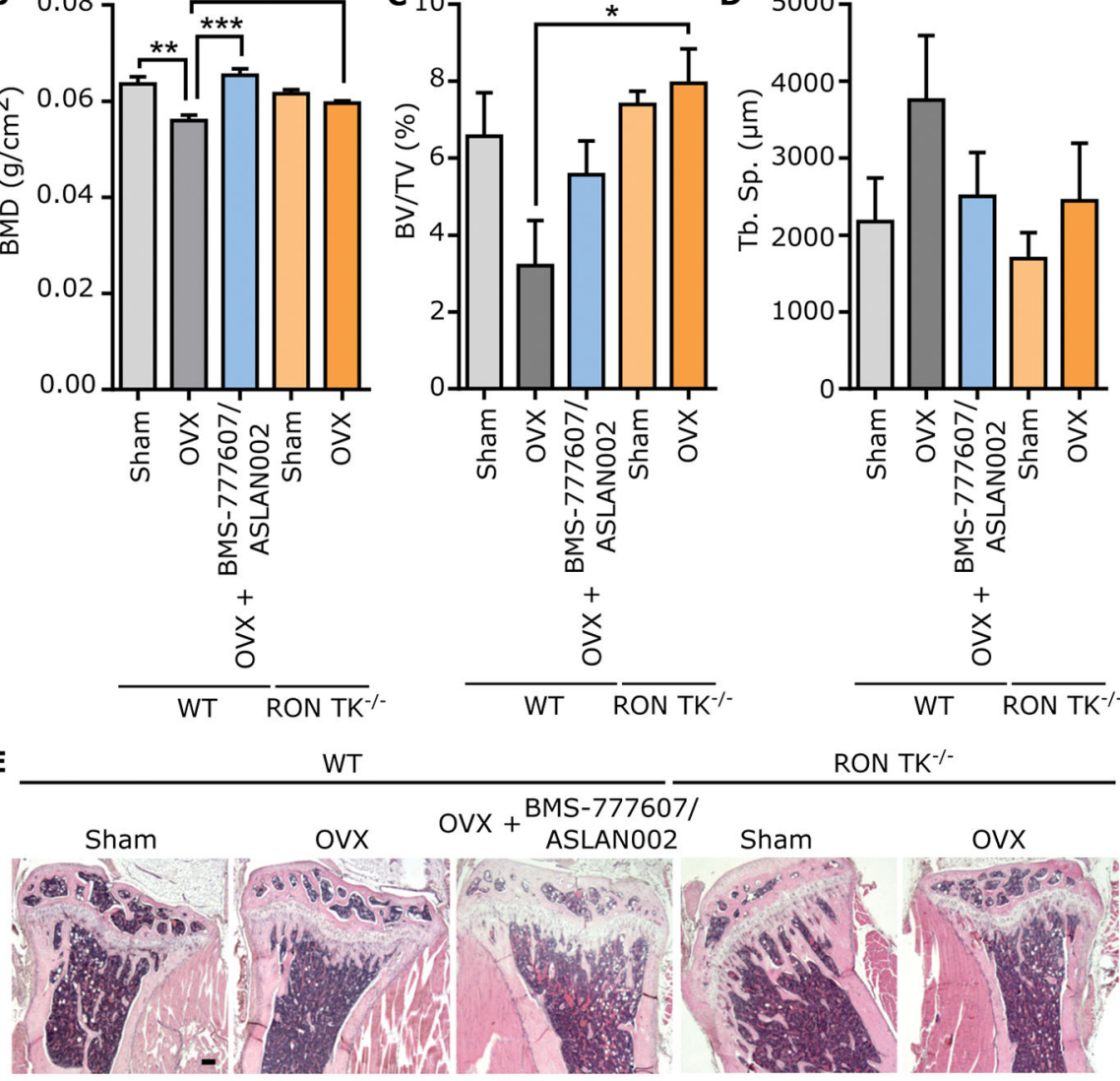

Fig. 5. Loss of RON activity protects from osteoporotic bone loss

(A) Representative $\mu \mathrm{CT}$ images of the proximal tibia (axial view of the metaphyseal region) from WT and RON TK ${ }^{-1-}$ mice 28 days after ovariectomy (OVX) or sham operation. Treatment with BMS-777607/ASLAN002 began 1 day after ovariectomy. Mice were euthanized 28 days after ovariectomy for analysis. (B) Quantification of bone mineral density (BMD) in the metaphyseal region of the tibia determined by dual-energy $\mathrm{X}$-ray absorptiometry (DXA) ( $\mathrm{n}=5$ per group); $* \mathrm{p}=0.027, * * \mathrm{p}=0.0032, * * * \mathrm{p}=0.0007$, two-tailed, unpaired Welch's t-tests. (C) Quantification of trabecular bone volume (BV) in the tibia expressed as percent total volume (TV), determined by bone histomorphometry analysis (n=5 per group); * $\mathrm{p}=0.014$, two-tailed, unpaired Welch's t-test. (D) Quantification of trabecular separation (Tb. Sp.) in the tibia ( $n=5$ per group), two-tailed, unpaired Welch's t- 
tests. (E) Representative sections of the tibia from each group stained with hematoxylin and eosin; scale bar, $50 \mu \mathrm{m}$. 

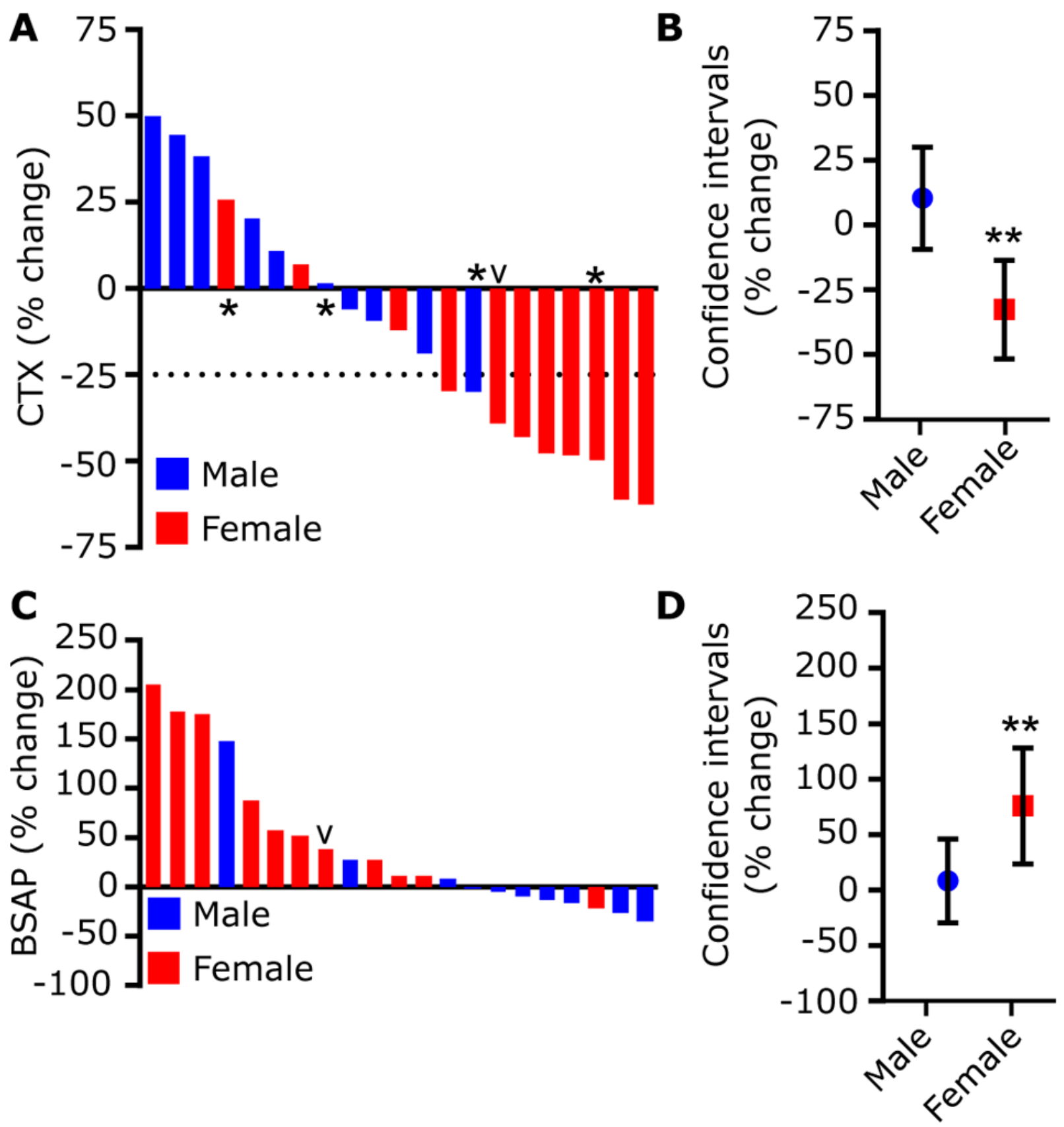

Fig. 6. The RON inhibitor BMS-777607/ASLAN002 reduces bone turnover in humans (A) Percent change in plasma CTX levels (compared to baseline prior to drug treatment) in blood plasma of 21 patients that received BMS-777607/ASLAN002 for at least 15 days in a Phase 1 clinical trial. Most patients received BMS-777607/ASLAN002 for 28 days; values reported correspond to the difference between baseline (day 0) and the 28-day time point. Exceptions in duration of treatment and CTX testing are noted ( $* 15$ days). Blue bars=males, red bars=females. Arrowhead denotes a patient less than 50 years of age (42 years). (B) Ninety-five percent confidence intervals for percent change in CTX for males and females; $* * \mathrm{p}=0.0035$, one-sample t-test versus a hypothetical mean of 0 (no change following 
treatment compared to baseline). (C) Percent change in bone-specific alkaline phosphatase (BSAP) levels (compared to baseline) in blood plasma of 21 patients that received BMS-777607/ASLAN002 for 28 days. 18 of the patients are also shown in (A). (D) Ninetyfive percent confidence intervals for percent change in BSAP for males and females; $* * \mathrm{p}=0.0090$, one-sample $\mathrm{t}$-test versus a hypothetical mean of 0 (no change following treatment compared to baseline). Blue bars=males, red bars=females. 